\title{
CALCULATING STATIC DEFORMATIONS FROM QUICK-RELEASE ACCELEROGRAMS
}

\author{
Bruce M. Douglas' \\ Emmanuel A. Maragakis² \\ and Bhabananda Nath ${ }^{3}$
}

\begin{abstract}
This paper outlines a new method for performing base line corrections on accelerograms generated by the quick-release dynamic testing method. These accelerograms are produced when highway bridges are subjected to dynamic excitations by initially deforming the bridge structure and subsequently quick-releasing the loads causing the deformation. This base line correction method is developed in such a way that the step function character of the quick-release base line is preserved. It is this feature which allows the static deformations of the structure to be recovered by integrating the accelerograms. The reliability of the method is demonstrated by a series of laboratory measurements comparing the displacement time series obtained by double integration to independently measured displacement responses. These laboratory comparisons indicate that the offset displacements are accurate to within about $5 \%$ on the average. The method was applied on accelerograms obtained during a quick-release full-scale test of the Meloland Road Overcrossing, and some examples of this application are presented.
\end{abstract}

\section{INTRODUCTION}

For the past 12 years or so, the University of Nevada has been conducting quick-release dynamic tests on highway bridges in order to determine the dynamic properties of the structures [Refs. 6, 7, 8]. In these tests, the bridge structure is first deformed by hydraulic rams; then high amplitude dynamic motions are created by simultaneously quick-releasing the hydraulic fluid from the hydraulic jacks. During the course of the experiments, high density accelerometer arrays are moved around the structure to measure the dynamic responses of the entire structure including the foundations. As a result, the detailed acceleration response of the structure is obtained as a direct consequence of the quick-release tests. Based on the acceleration response, a complete modal analysis of the structure can be performed and its dynamic characteristics can be determined in detail. However, the direct measurement of the static deformation of the structure under the initially applied hydraulic ram loads ordinarily requires the use of fixed reference frames. In the past,

1 Professor of Civil Engineering, University of Nevada, Reno, NV 89557

Associate Professor of Civil Engineering, University of Nevada, Reno, NV 89557

Graduate Research Assistant, University of Nevada, Reno, NV 89557 a few selected static deformations of the structure were measured by using dial gages or other displacement transducers attached to fixed references. This procedure is very inconvenient, time consuming, and expensive. The expense and inconvenience were the motivating factors driving the development of an accurate method of integrating quick-release accelerograms to displacements.

Such a method can automatically produce the static displacements of the structure under the initially applied loads. Therefore, by integrating the acceleration records obtained from the quick-release tests at various points of the structure, the complete static deformation profile of the bridge can be obtained as a by-product of the dynamic response of the structure.

The calculation of displacement time histories by integrating measured acceleration records is a very difficult problem which has been addressed by a number of researchers $[2,3,4,5,10,11,12,14]$. The characteristic of general accelerograms which makes their successful integration for accurate displacement time histories so difficult is that the accelerometer transducer produces a large signal for the high frequency content but a very small signal for the simultaneously recorded long period content. It is this low frequency information in the signal which principally influences the final base line of the displacement time history. While the signal to noise ratio for the high frequency 
information may be excellent, the signal to noise ratio for the long period part of the accelerogram will be much lower. This low signal to noise ratio causes serious problems when the accelerograms are doubly integrated.

Structural vibration accelerograms produced by the quick-release method are a special case where the character of the final base line is known. The final base line is offset by the amount of the displacement induced by the quick-release loads and is otherwise flat. In other words, it is a step function. This demands a special type of base line correction algorithm. The algorithm required must allow the offset displacement to occur in the corrected displacement trace and then be a flat straight line after the offset. By extending the earlier work of Brady [4], it was possible to develop such an algorithm, which is the subject of this paper.

The objectives of this paper are:

(i) To outline the development of a base line correction algorithm that allows the reliable integration of accelerograms obtained from quick-release experiments to displacements and which automatically produces the static displacement of the structure under the initially applied quick-release loads;

(The method presented herein can be applied on accelerograms obtained from quick-release dynamic tests, but it does not solve the problem of integrating arbitrary accelerograms to displacements.)

(ii) To describe a series of laboratory quick-release experiments that were performed in order to demonstrate the validity of the integration method; and

(iii) To describe briefly the application of the method on some quick-release accelerograms obtained during a full-scale quick-release dynamic test of a bridge in Southern California.

\section{MATHEMATICAL FORMULATION OF THE INTEGRATION TECHNIOUE}

The measured acceleration record was adjusted by applying a polynomial base line correction of the order $n$. The need for the application of this base line correction has been addressed by other researchers in the past [4].

After the polynomial base line correction is applied to the measured acceleration trace, the following formula is obtained for the corrected acceleration.

$a^{*}(t)=a(t)-\left(c_{0}+c_{1} t+c_{2} t^{2}+\ldots+c_{n} t^{n}\right)=a(t)-\sum_{m=0}^{n} c_{m} t^{m}$

In the expression above, the $c_{m}$ 's and $n$ are the coefficients and the order of the polynomial correction respectively. The coefficients and the order of the polynomial will be evaluated using methods which will be described later in this section.

Integrating Eq. (1) to velocity and then to displacement yields:

$$
\begin{aligned}
v^{*}(t) & =\int_{0}^{t}\left[a(t)-\sum_{m=0}^{n} c_{m} t^{m}\right] d t=v(t)-\sum_{m=0}^{n} \frac{c_{m}}{m+1} t^{m+1}+c_{n+1} \\
d^{*}(t) & =\int_{0}^{t}\left[v(t)-\sum_{m=0}^{n} \frac{c_{m}}{m+1} t^{m+1}+c_{n+1}\right] d t \\
& =d(t)-\sum_{m=0}^{n} \frac{c_{m}}{(m+1)(m+2)} t^{m+2}+c_{n+1} t+c_{n+2}
\end{aligned}
$$

In the expressions above, $v^{*}(t)$ and $d^{*}(t)$ are the corrected velocity and displacement respectively, $v(t)$ and $d(t)$ are the velocity and displacement obtained by integrating the measured acceleration record without any correction, and $c_{n+1}$ and $c_{n+2}$ are constants of integration.

The unknown coefficients in the expressions above now need to be determined. Previously, Brady [4], who applied a second-order polynomial correction on the acceleration, required that the velocity have a minimum mean square value. This procedure had some merit in this application because it was known that the original and final velocities were zero, and minimizing the mean square of velocity gave the resulting velocity trace a flat base line consistent with the physical problem. The mean square of the displacement could also be minimized, but this clearly would only be applicable to those cases where it was known that the final base line of the displacement trace was flat.

In the case of the quick release problem, it is known a priori that the base line of the displacement is going to be a horizontal straight line shifted by an amount equal to the unknown release displacement. Therefore, in this case, the unknown coefficients of equation ( 3 ) can be determined by operating directly on the displacement. Furthermore, operation on the displacement will directly produce the value of the constant $c_{n+2}$ which, as can be seen from (3), is the value of the release or offset displacement.

In order that the displacement $d^{*}(t)$ have a minimum mean square value, the following equations must hold.

$$
\frac{\partial}{\partial C_{i}} \int_{0}^{s}\left[d^{*}(t)\right]^{2} d t=0, i=0,1,2, \ldots, n+2
$$

In the above equations, $S$ is the total length of the record. Substituting the expression of $d^{*}(t)$ from expression (3) into 
expression (4) and performing all the necessary algebraic calculations yields the following system of equations.

$$
\begin{gathered}
\sum_{m=0}^{n} \frac{1}{(m+1)(m+2)(m+r+3)} C_{m} S^{m+r+3}-\frac{1}{r+2} C_{n+1} s^{r+2} \\
-\frac{1}{r+1} C_{n+2} S^{r+1}=I_{r} \quad r=0,1,2, \ldots, n+2 \\
\text { where: } I_{r}=\int_{0}^{s} d(t) t^{r} d t
\end{gathered}
$$

Equation (5) is the condensed form of a system of $n+2$ equations with unknowns the $n+2$ coefficients which appear in expression (3). Solution of this system will obviously produce the values of the unknown coefficients. However, for the system to be solved, it is necessary to evaluate the integrals $I_{r}$ which are given by expression (5). The evaluation of these integrals is fully described in Appendix II. For the solution of the system of equations (5), a computer program was written which, for a given order $\mathrm{n}$ of the polynomial base line correction, solves the system and produces the unknown coefficients. These coefficients are then substituted in Eq. (3) to produce the corrected displacement record.

For the determination of the "best" order $n$, the coefficient of multiple determination which is described by Al-Khafaji and Tooley [1] was used. In general, if a set of given data points $\left(x_{i}, f_{i}\right)$ is approximated by a functional approximation $F(x)$ determined by curve fitting techniques, the coefficient of multiple determination $R^{2}$ is used to relate the deviation of the data points $\left(x_{i}, f_{i}\right)$ from the functional approximation $F_{i}$ to the average functional value $\bar{f}$ through the following equation.

$$
R^{2}=\frac{\sum_{i=1}^{N}\left(F_{i}-F\right)^{2}}{\sum_{i=1}^{N}\left(f_{i}-F\right)^{2}}
$$

In the expression above, $\mathrm{N}$ is the total number of data points. The closer the value of $R^{2}$ is to unity, the better the functional approximation $\mathbf{F}$.

In our case, the integration technique for accelerograms which was described above was used to integrate acceleration records for which the corresponding displacements records were measured with LVDT transducers. In this case, the coefficient of multiple determination was applied on the measured displacement records.

$$
R_{d}^{2}=\frac{\sum_{i=1}^{N}\left(d^{*}(t)-d(t)\right)^{2}}{\sum_{i=1}^{N}(\hat{d}(t)-d(t))^{2}}
$$

In the expression above, $\hat{d}(t)$ is the displacement record measured by the LVDT and $\bar{d}(t)$ is the average of this record.
The coefficient $R_{d}^{2}$ was evaluated for various values of the order $n$ of the polynomial correction. The value of $n$ that yielded a coefficient $R_{d}^{2}$ closest to unity was chosen as the optimum order of the polynomial correction.

For these particular laboratory experiments, LVDT measurements were available. In a real field problem however, LVDT measurements are not usually possible because of the difficulty of establishing a fixed reference frame. In these cases, an alternate technique for the determination of the optimum $n$ is considered. In this case, the coefficient of multiple determination is applied on the recorded acceleration record.

$$
R_{a}^{2}=\frac{\sum_{i=1}^{N}\left(a^{*}(t)-\bar{a}^{*}(t)\right)^{2}}{\sum_{i=1}^{N}(a(t)-\bar{a}(t))^{2}}
$$

As before, the optimum $\mathrm{n}$ is the one that yields a coefficient $R^{2}$ closest to unity. The implication of this is that the optimum $n$ causes a base line correction which least disturbs the original measured acceleration trace (obviously, $\mathrm{n}$ is greater than zero). The experimental results of the above described procedure for choosing $n$ are discussed in detail in the next section of this paper.

\section{EXPRIMENTAL VERIFICATION OF THE METHOD}

In order to establish confidence in the reliability of the new correction algorithm, a series of "quick-release" experiments were performed at the dynamics lab of the University of Nevada, Reno. To perform these experiments, a three-story experimental frame was built in the laboratory. This frame was built to simulate the general dynamic properties of full-scale bridges and to measure both displacement and acceleration traces simultaneously. Figure 1 shows the frame with its three heavy steel masses attached to slender steel columns and the quick-release hooks at each story. Pulling and releasing these hooks produces quick-release motions very similar to those obtained in the field on full-scale bridges except that the damping values are much smaller. Furthermore, the frame was proportioned in such a way that the frequencies are in a realistic range for full-scale bridges. In this case, the natural frequencies are $1.8,5.2$, and 7.6 hz. Figure 2 shows a typical accelerometer transducer attached to the mass, while Fig. 3 shows the LVDT displacement transducer attached to the mass and to the external fixed reference frame. Both the acceleration and displacement time histories of the frame were recorded using the Kinemetrics Dataseis field data acquisition system. This system has a 64-channel recording capability with 24 FBA 11 force balance accelerometers. The full-scale peak-to-peak signal is digitized with a resolution of 4096 . 


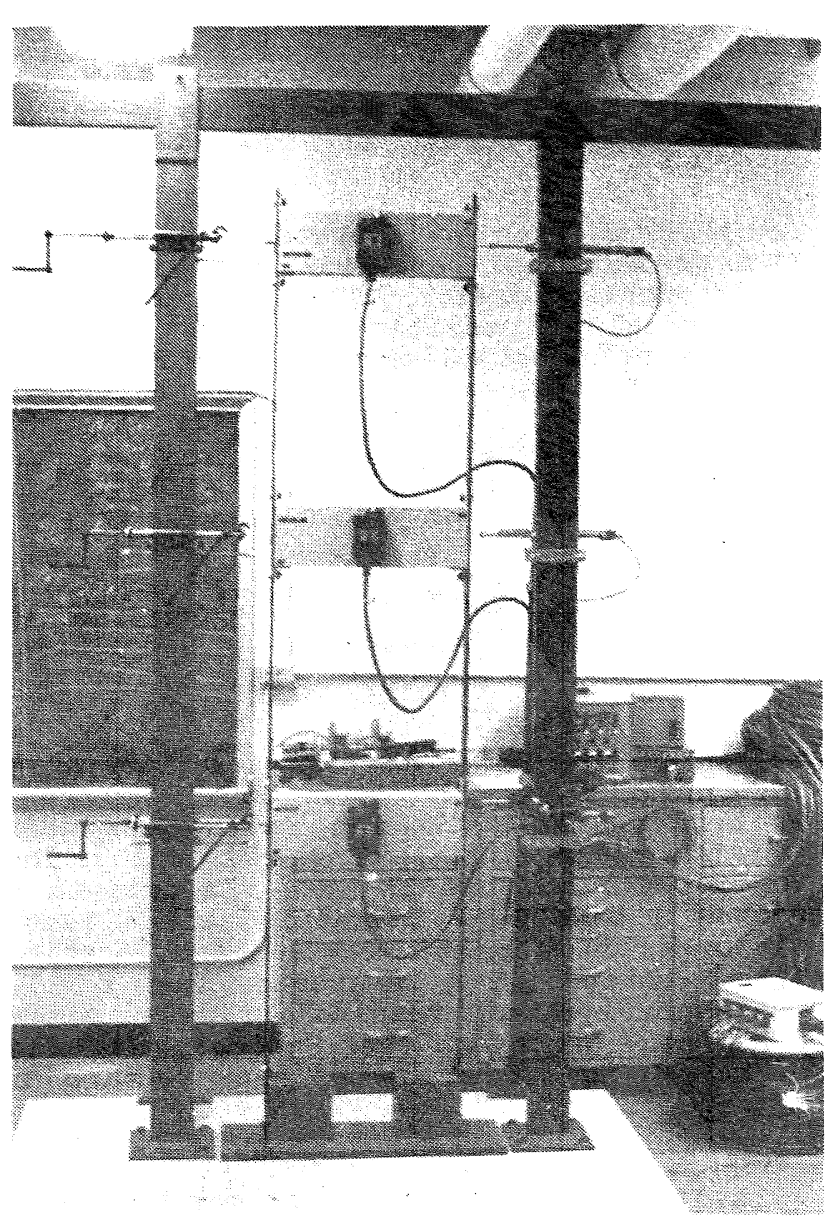

FIGURE 1. EXPERIMENTAL FRAME
I'o study the effectiveness of the base line corrnction routine developed in this paper, a serles of parametric experimental studies were conducted on the test frame. In these experiments, the frame was subjected to quick-release excitations at the different stories by pulling and releasing the appropriate hooks; and the acceleration and time histories were recorded at all three storles each time. Table 1 consists of all the cases studied where the frame was quick-released at story 1 , while Table 2 contains the cases where story 2 was the quick-release story. In sequence, the nine columns of the tables indicate: 1 ) the story from which the experimental acceleration and displacement time histories were obtained, 2) their record lengths in seconds, 3) the digitization rate in samples per second, 4) the corner frequency of the low pass filter being used on the analog data prior to digitization, 5) whether the $0.1 \mathrm{hz}$ fixed corner frequency high pass filter was on or off, 6) the optimum order of the correction polynomial as determined by the best-fit criteria discussed above applied relative to the measured displacement trace, 7) the offset displacement calculated by the correction algorlthm, 8) the directly measured offset displacement, and 9) the percentage of error between the calculated and measured offset displacement.

Figure 4 shows an example of Iwan's method [11, 12] applied to a 20-second quick-release accelerogram at the second story of the test frame. The upper trace is the accelerogram digitized at 100 samples per second. The second trace shows the velocity time history obtained by the integration of the corrected accelerogram, and the third trace is the displacement time history obtained by a double integration of

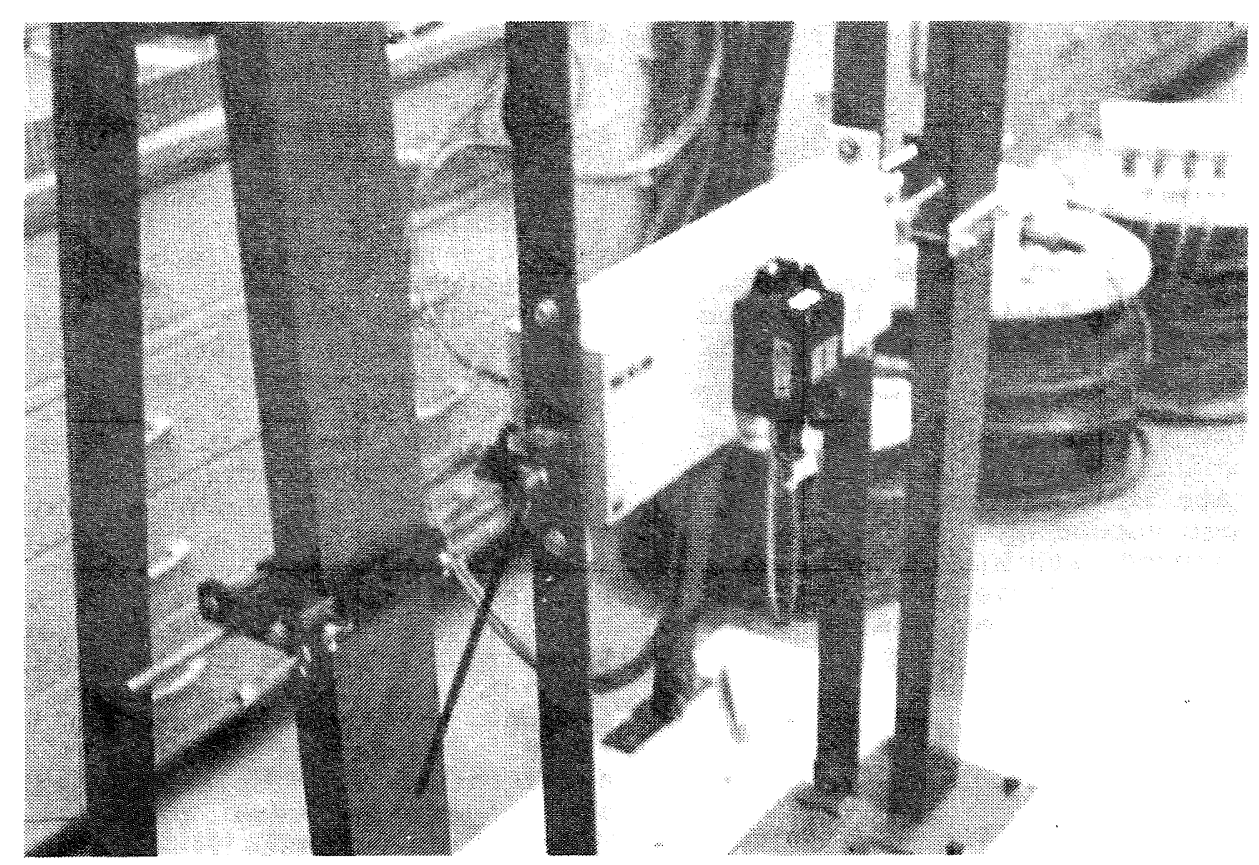

FIGURE 2. ACCELEROMETER TRANBDUCER 
TABLE 1. Tabular Results of Experiments Involving Response of stories Two and Three with a First-story Relesso

\begin{tabular}{|c|c|c|c|c|c|c|c|c|}
\hline storey & $\begin{array}{l}\text { Record } \\
\text { Length } \\
\text { (sec.) }\end{array}$ & $\begin{array}{c}\text { Bamplo } \\
\text { Rato } \\
\text { (8PB) }\end{array}$ & $\begin{array}{c}\text { Low Pass } \\
\text { Filter } \\
\text { (Hz) }\end{array}$ & $\begin{array}{c}\text { High Pass } \\
\text { Filter }\end{array}$ & order & $\begin{array}{c}\text { Calculated } \\
\text { Disp. } \\
\text { (cm) }\end{array}$ & $\begin{array}{c}\text { LVDT } \\
\text { Display } \\
(\mathrm{cm})\end{array}$ & $\begin{array}{c}\text { Error } \\
8 \\
\end{array}$ \\
\hline 2 & 20.0 & 100.0 & $12.5 \mathrm{~Hz}$ & ON & 3 & -1.9392 & -2.012 & $3.6 \%$ \\
\hline 3 & 20.0 & 100.0 & $12.5 \mathrm{~Hz}$ & ON & 5 & -1.9502 & -2.016 & 3.38 \\
\hline 2 & 20.0 & 50.0 & $12.5 \mathrm{~Hz}$ & ON & 4 & -1.9603 & -2.004 & 2.28 \\
\hline 3 & 20.0 & 50.0 & $12.5 \mathrm{~Hz}$ & ON & 6 & -1.9811 & -2.009 & $1.4 \%$ \\
\hline 2 & 20.0 & 200.0 & $12.5 \mathrm{II} 7$ & ON & 6 & -1.8813 & -1.989 & $5.4 \%$ \\
\hline 3 & 20.0 & 200.0 & $12.5 \mathrm{liz}$ & ON & 7 & -1.9159 & -1.9943 & $3.9 \%$ \\
\hline 2 & 10.0 & 100.0 & $12.5 \mathrm{llz}$ & $\mathrm{ON}$ & 3 & -1.8762 & -1.9903 & $5.7 \%$ \\
\hline 3 & 10.0 & 100.0 & $12.5 \mathrm{~Hz}$ & ON & 4 & -2.0813 & -1.999 & $4.1 \%$ \\
\hline 2 & 60.0 & 100.0 & $12.5 \mathrm{~Hz}$ & ON & 7 & -1.9769 & -1.9973 & $1.0 \%$ \\
\hline 3 & 60.0 & 100.0 & $12.5 \mathrm{~Hz}$ & ON & 8 & -1.828 & -1.993 & $8.2 \%$ \\
\hline 2 & 20.0 & 100.0 & $12.5 \mathrm{~Hz}$ & OFF & 2 & -1.9085 & -1.962 & $2.7 \frac{9}{6}$ \\
\hline 3 & 20.0 & 100.0 & $12.5 \mathrm{~Hz}$ & ON & 5 & -1.9694 & -1.9655 & $0.1 \%$ \\
\hline 2 & 20.0 & 100.0 & $2.5 \mathrm{IIz}$ & ON & 3 & -1.818 & -2.0174 & $9.9 \%$ \\
\hline 3 & 20.0 & 100.0 & $2.5 \mathrm{~Hz}$ & $\mathrm{ON}$ & 5 & -1.838 & -2.022 & $9.0 \%$ \\
\hline 2 & 20.0 & 100.0 & $5.0 \mathrm{~Hz}$ & ON & 4 & -1.9295 & -1.9488 & $1.0 \%$ \\
\hline 3 & 20.0 & 100.0 & $5.0 \mathrm{~Hz}$ & ON & 5 & -1.893 & -1.9528 & $3.0 \%$ \\
\hline
\end{tabular}

TABLE 2. Tabular Results of Experiments Involving All Three stories with a second-story Release

\begin{tabular}{|c|c|c|c|c|c|c|c|c|}
\hline Storey & $\begin{array}{l}\text { Record } \\
\text { Length } \\
\text { (sec.) }\end{array}$ & $\begin{array}{c}\text { Sample } \\
\text { Rate } \\
\text { (SPS) }\end{array}$ & $\begin{array}{c}\text { Low Pass } \\
\text { Filter } \\
(\mathrm{Hz})\end{array}$ & $\begin{array}{c}\text { High pass } \\
\text { Filter }\end{array}$ & Order & $\begin{array}{c}\text { Calculated } \\
\text { Disp. } \\
(\mathrm{cm})\end{array}$ & $\begin{array}{c}\text { LVDT } \\
\text { Disp. } \\
\text { (cm) }\end{array}$ & $\begin{array}{c}\text { Error } \\
\frac{8}{8}\end{array}$ \\
\hline 1 & 20.0 & 100.0 & $12.5 \mathrm{~Hz}$ & ON & 5 & -1.4666 & -1.5544 & $5.6 \%$ \\
\hline 2 & 20.0 & 100.0 & $12.5 \mathrm{ll} \mathrm{z}$ & ON & 4 & -2.9151 & -3.1033 & $6.1 \%$ \\
\hline 3 & 20.0 & 100.0 & $12.5 \mathrm{~Hz}$ & ON & 5 & -3.0212 & -3.1577 & $4.2 \%$ \\
\hline 1 & 40.0 & 100.0 & $12.5 \mathrm{~Hz}$ & ON & 8 & -1.3816 & -1.4043 & $1.6 \%$ \\
\hline 2 & 40.0 & 100.0 & $12.5 \mathrm{~Hz}$ & ON & 7 & -2.6320 & -2.8033 & $6.1 \%$ \\
\hline 3 & 40.0 & 100.0 & $12.5 \mathrm{~Hz}$ & ON & 7 & -2.7539 & -2.8472 & $3.3 \%$ \\
\hline 1 & 20.0 & 200.0 & $12.5 \mathrm{~Hz}$ & ON & 7 & -1.4626 & -1.5568 & 6.18 \\
\hline 2 & 20.0 & 200.0 & $12.5 \mathrm{~Hz}$ & ON & 5 & -2.8978 & -3.1072 & $6.7 \%$ \\
\hline 3 & 20.0 & 200.0 & $12.5 \mathrm{~Hz}$ & ON & 5 & -2.9400 & -3.1676 & $7.2 \%$ \\
\hline
\end{tabular}

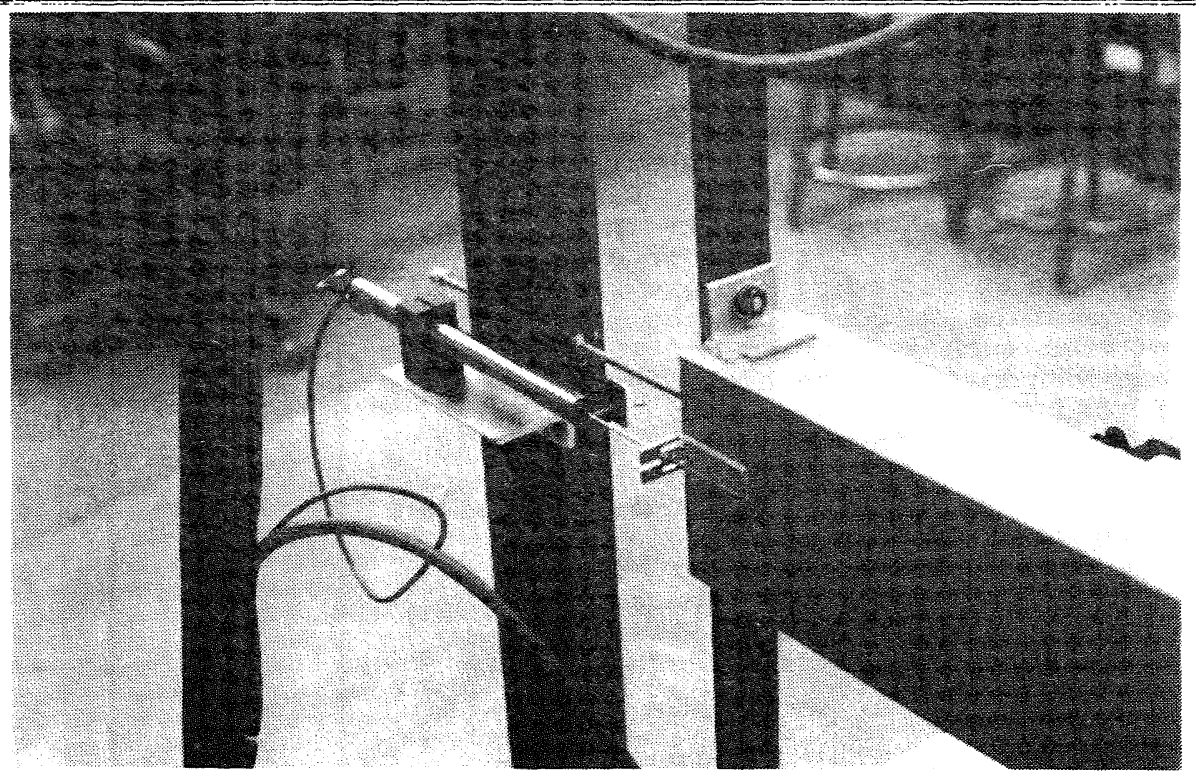

FIGURE 3. LVDT DIBPLACEMENT TRANSDUCER 
the corrected accelerogram. The last 5.7 seconds of the uncorrected velocity trace were used to obtain the final offset correction. As was observed by these researchers, the starting and ending times for the intermediate range correction did not strongly influence the final result. The third trace in Fig. 4 represents the best attempt to flatten the baseline after the offset displacement. As can be seen, the resulting displacement time history is much improved compared to the case where no correction would have been applied, but it is not sufficiently precise to give a reliable estimate of the offset displacement.

Figure 5 represents the results of the basic reference experiment. The low pass corner was set at $12.5 \mathrm{hz}$, while the frequency of the highest mode is $7.6 \mathrm{hz}$. The sample rate was set at 100 samples per second; this is sufficiently high to describe the highest frequency waveforms accurately. The acceleration and displacement time histories were recorded at the second story.

The upper trace of Fig. 5 represents the accelerogram with a peak acceleration of $79 \%$ of gravity. The middle trace represents the velocity time history, and the bottom block contains the measured displacement time history (dashed line) along with the displacement time history obtained by integration after using the optimum order 3 base line correction polynomial (solid line). In this case, the agreement between the measured and calculated displacement is excellent with the percent of error in the offset displacement being only 3.6\%. It should be observed here that the integration method produced the correct displacement time history even though a $0.1 \mathrm{hz}$ fixed corner high pass filter was used when the data were collected.

Figures 6 and 7 illustrate the performance of the correction scheme when the sample rate is varied away from that of the basic case. The sample rates in Figs. 6 and 7 are 50 and 200 respectively. As can be seen, the agreement between the calculated and observed traces is excellent and the error in the calculated offset displacements is $2.2 \%$ and $5.4 \%$ respectively. A short 10-second record is depicted in Fig. 8, while a long 60-second record is shown in Fig. 9. The agreement for the 10-second case is excellent, but the 60-second record shows that it is not possible to get a perfectly flat base line with such a long trace. To demonstrate what happens when the high pass filter is not used on the analog data, a second experiment was performed with the same parameters as in the basic case described above. The result of this experiment is depicted in Fig. 10. Again, the agreement is excellent and the order of optimum correction polynomial was reduced from 3 to 2 . Similar results were obtained when the frame was released from the second story.

In all of the cases shown in Tables 1 and 2 , the optimum order of the correction polynomial was estimated based on the coefficient $\mathrm{R}_{\mathrm{d}}^{2}$, the evaluation of which, as described in the previous section of the paper, requires the availability of measured displacement data. However, as explained before in this paper, measured displacement traces will be available in very few cases, if at all, in a field experiment. In these experiments where the measured displacement traces are not available, the optimum order of the correction polynomial can be evaluated using the coefficient $R^{2}$ as explained in the previous section of the paper. The use of the coefficient $R_{a}^{2}$ was tested on 14 of the 16 cases in Table 1 obtained from stories 2 and 3 , and the results are given in Table 3 . At the right side of the table, the optimum order obtained by using the coefficient $R_{d}^{2}$ and the actual error in the offset displacement are shown. To the left, the polynomial order obtained by using the coefficient $R^{2}$ is shown along with the error in the offset displacement associated with the base line correction of this order. It can be noted that the use of the coefficient $R^{2}$ picked the actual optimum polynomial order to within one degree except in one case; and, in this case, the difference in the offset displacement error is small. This occurs in some cases because the final results are not always sensitive to the polynomial order. From the left column, the average error is found to be $5.3 \%$; while the maximum error is observed to be 10.68 . It should be further noted that this maximum error is associated with the 60-second record where it is more difficult for the method to produce the correct base line over such a long trace.

\section{APPLICATION OF THE METHOD ON A FIELD TEST}

The integration technique described above was applied on the data obtained from the full-scale quick-release excitation of Meloland Bridge conducted May 23-26, 1988. This bridge is a two-span reinforced concrete box girder structure with a 208-foot deck monolithically connected to

TABLE 3. Application of the coefficient of Multiple Determination to the Acceleration Traces

\begin{tabular}{|c|c|c|c||}
\hline \multicolumn{2}{|c|}{ KEASURED ACCELERATION } & \multicolumn{2}{c|}{ MEASURED DISPLACEMENT } \\
\hline Order & Error & Order & Error \\
\hline 4 & $5.5 \%$ & 3 & $3.6 \%$ \\
4 & $5.6 \%$ & 5 & $3.3 \%$ \\
4 & $2.2 \%$ & 4 & $2.2 \%$ \\
6 & $1.4 \%$ & 6 & $1.4 \%$ \\
3 & $6.4 \%$ & 6 & $5.4 \%$ \\
8 & $5.5 \%$ & 7 & $3.9 \%$ \\
4 & $7.7 \%$ & 3 & $5.7 \%$ \\
3 & $0.1 \%$ & 4 & $4.1 \%$ \\
6 & $10.6 \%$ & 7 & $1.0 \%$ \\
8 & $8.2 \%$ & 8 & $8.2 \%$ \\
2 & $2.7 \%$ & 2 & $2.7 \%$ \\
6 & $0.2 \%$ & 5 & $0.1 \%$ \\
3 & $7.9 \%$ & 4 & $1.0 \%$ \\
4 & $3.9 \%$ & 5 & $3.0 \%$ \\
\hline
\end{tabular}


THREE STOREY FRAME MODEL U.N.R.

MAX ACC= $-699.03 \mathrm{CM} / \mathrm{S} / \mathrm{S}$ MAX VEL $=25.760 \mathrm{CM} / \mathrm{S}$. OFFSET 'DISP $=3.7186 \mathrm{CM}$
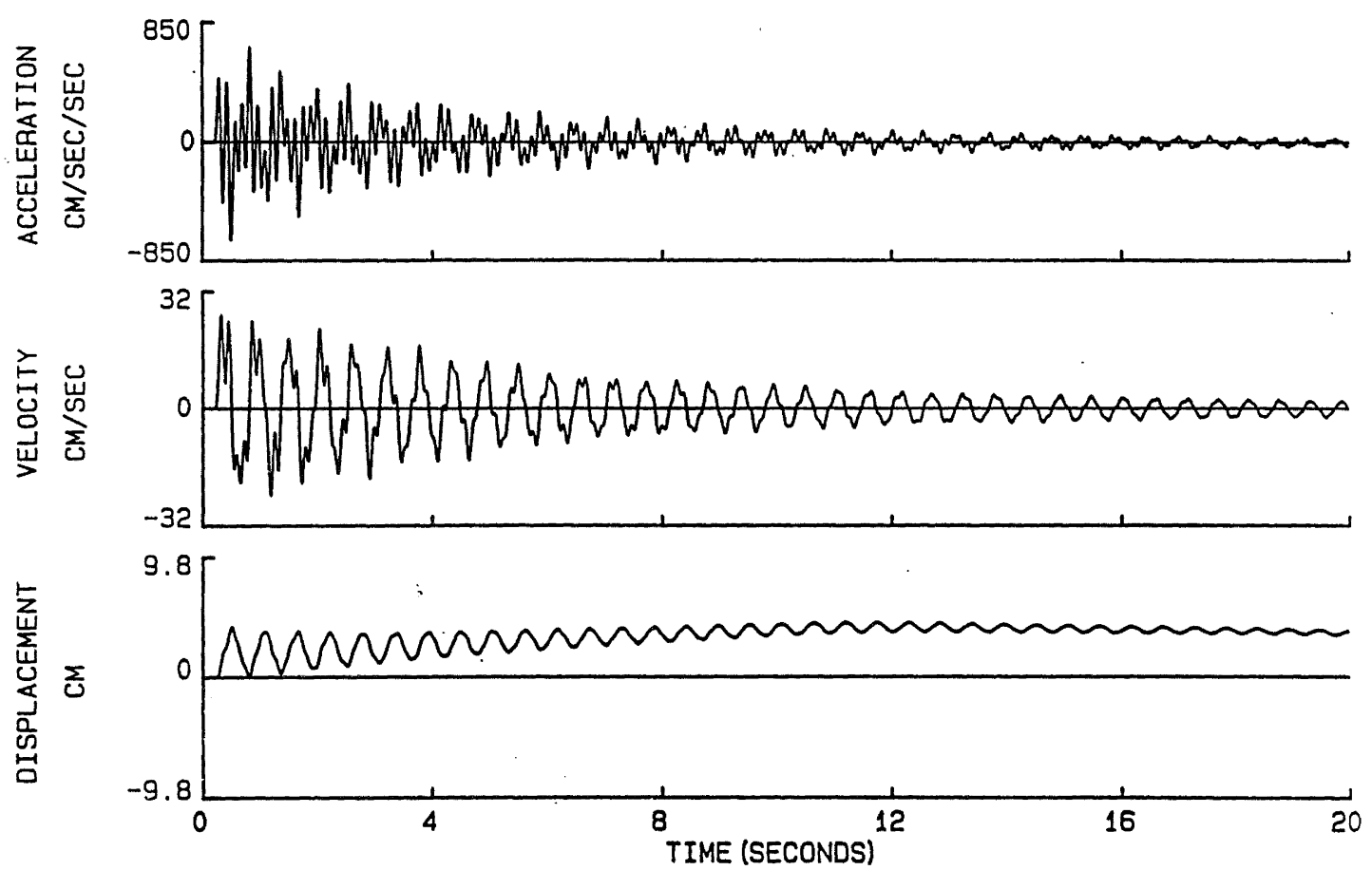

FIGURE 4. EXAMPLE OF THE APPLICATION OF IWAN'S METHOD

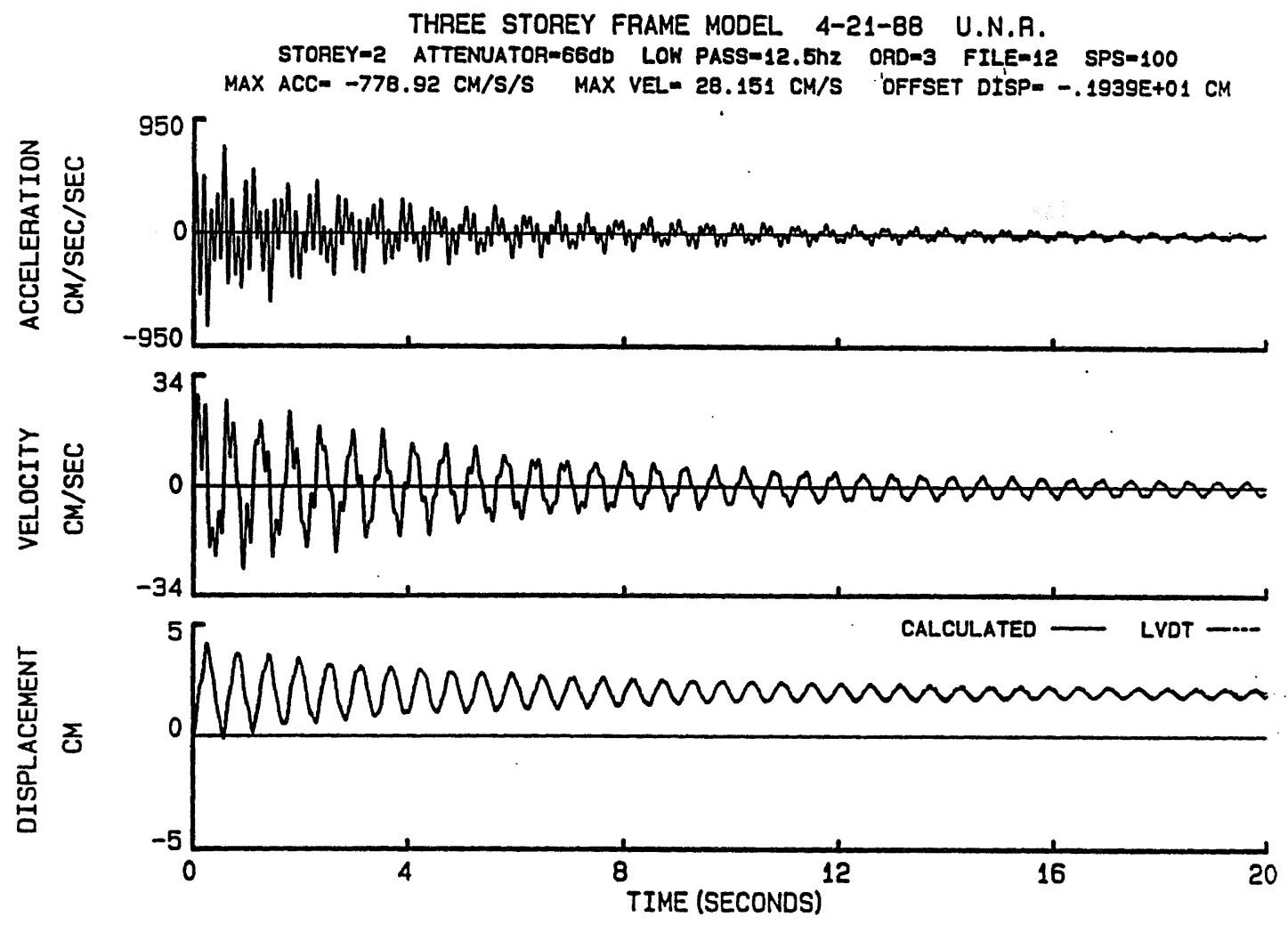

FIGURE 5. BASIC EXPERIMENT 
THREE STOREY FRAME MODEL 4-21-88 U.N.R.

MAX ACC $=-718.66 \mathrm{CM} / \mathrm{S} / \mathrm{S}$ MAX VEL- $26.365 \mathrm{CM} / \mathrm{S}$ OFFSET DISP= $-.1960 E+01 \mathrm{CM}$
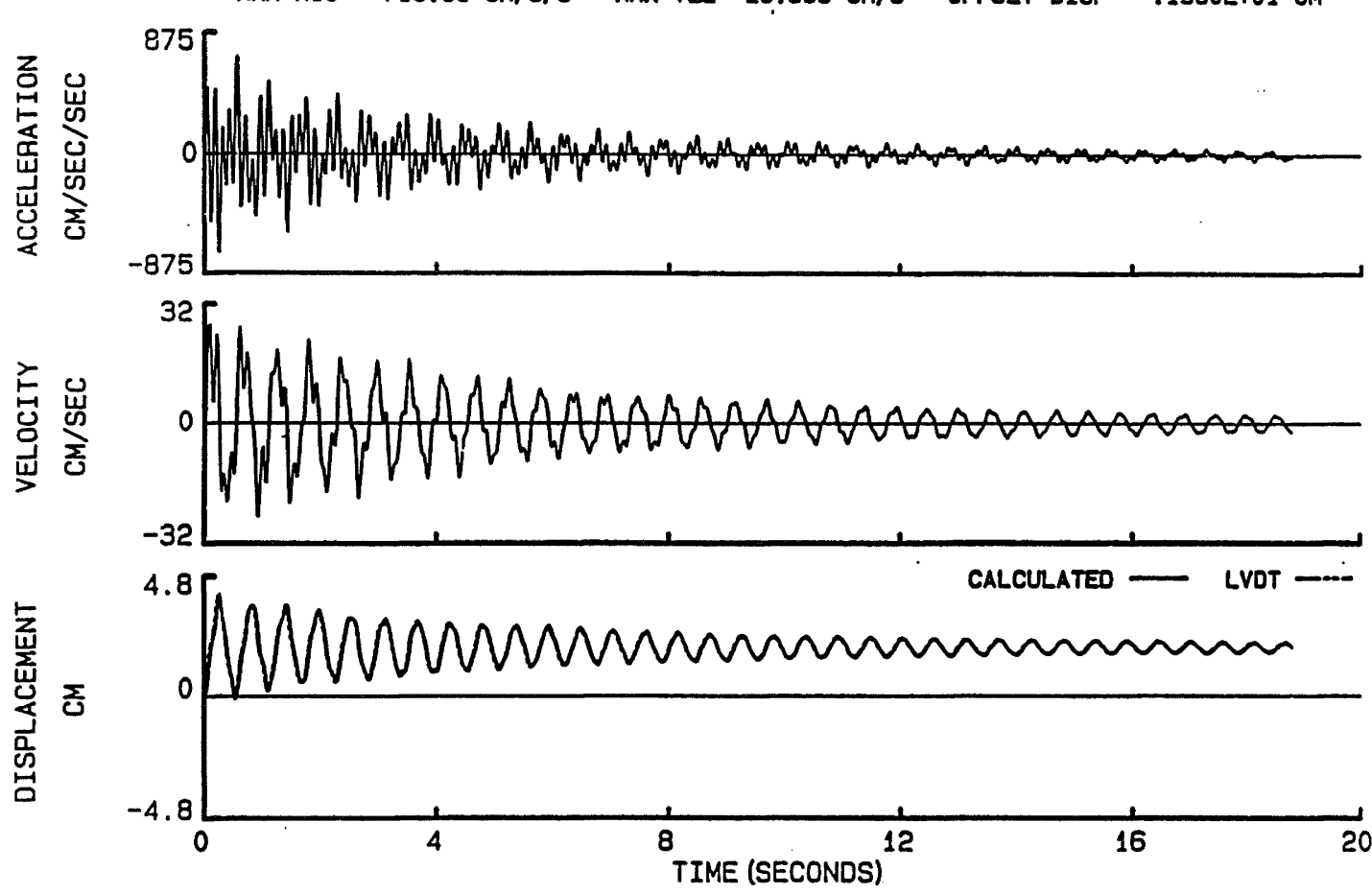

FIGURE 6. 50 SAMPLES PER SECOND EXPERIMENT

THREE STOREY FRAME MODEL 4-21-88 U.N.R. MAX ACC $-763.12 \mathrm{CM} / \mathrm{S} / \mathrm{S}$ MAX VEL- $27.658 \mathrm{CM} / \mathrm{S}$ OFFSET DISP= $-.1881 \mathrm{E}+01 \mathrm{CM}$
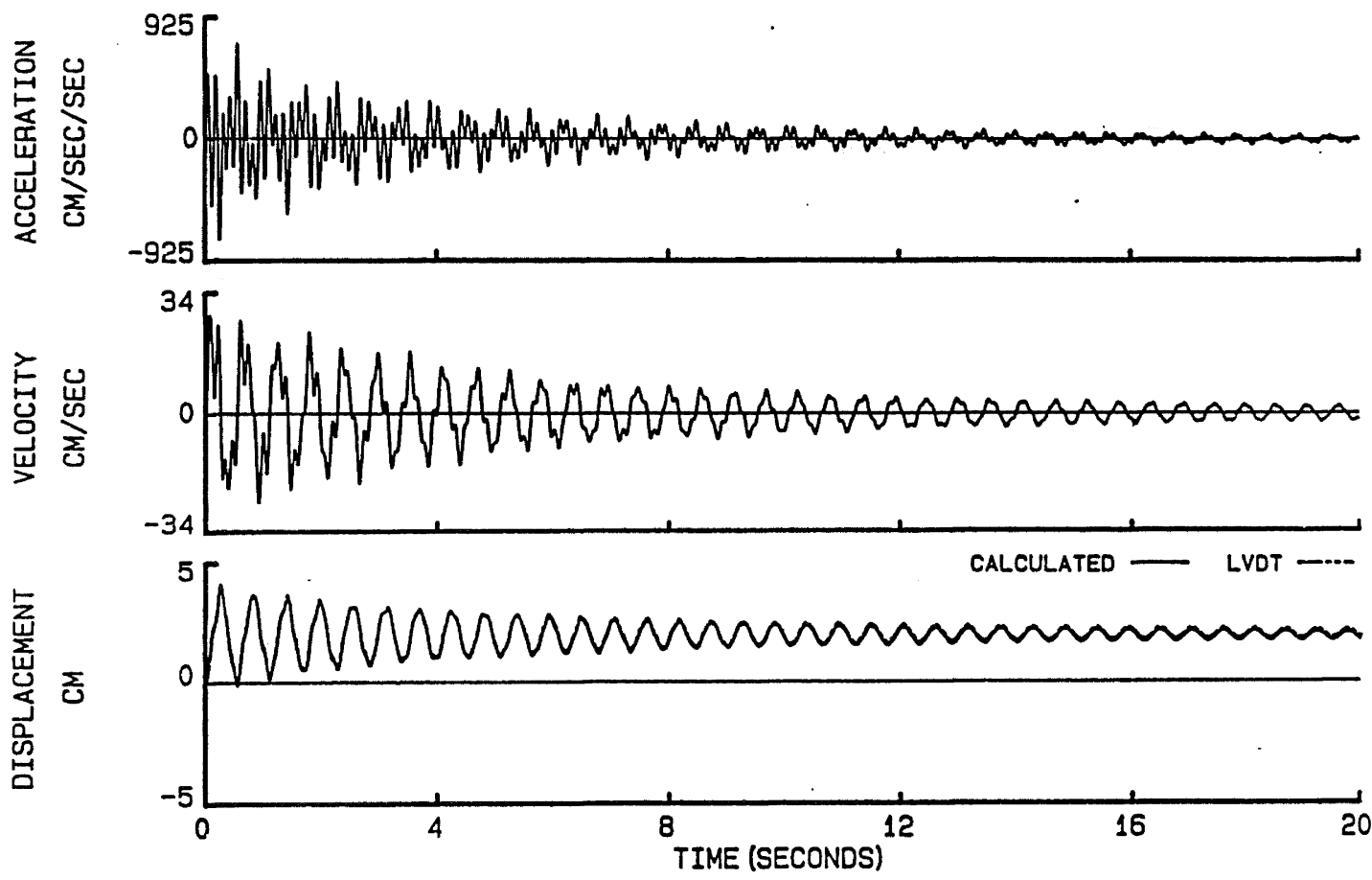

FIGURE 7. 200 SAMPLES PER SECOND EXPERIMENT 
THREE STOREY FRAME MODEL 4-21-88 U.N.R.

STOREY-2 ATTENUATOR-66db LOW PASS-12. Th2 ORD=3 FILE=16 SPS-100

MAX ACC $=-779.03 \mathrm{CM} / \mathrm{S} / \mathrm{S}$ MAX VEL $=27.815 \mathrm{CM} / \mathrm{S}$ 'OFFSET DISP- $-.1876 E+01 \mathrm{CM}$
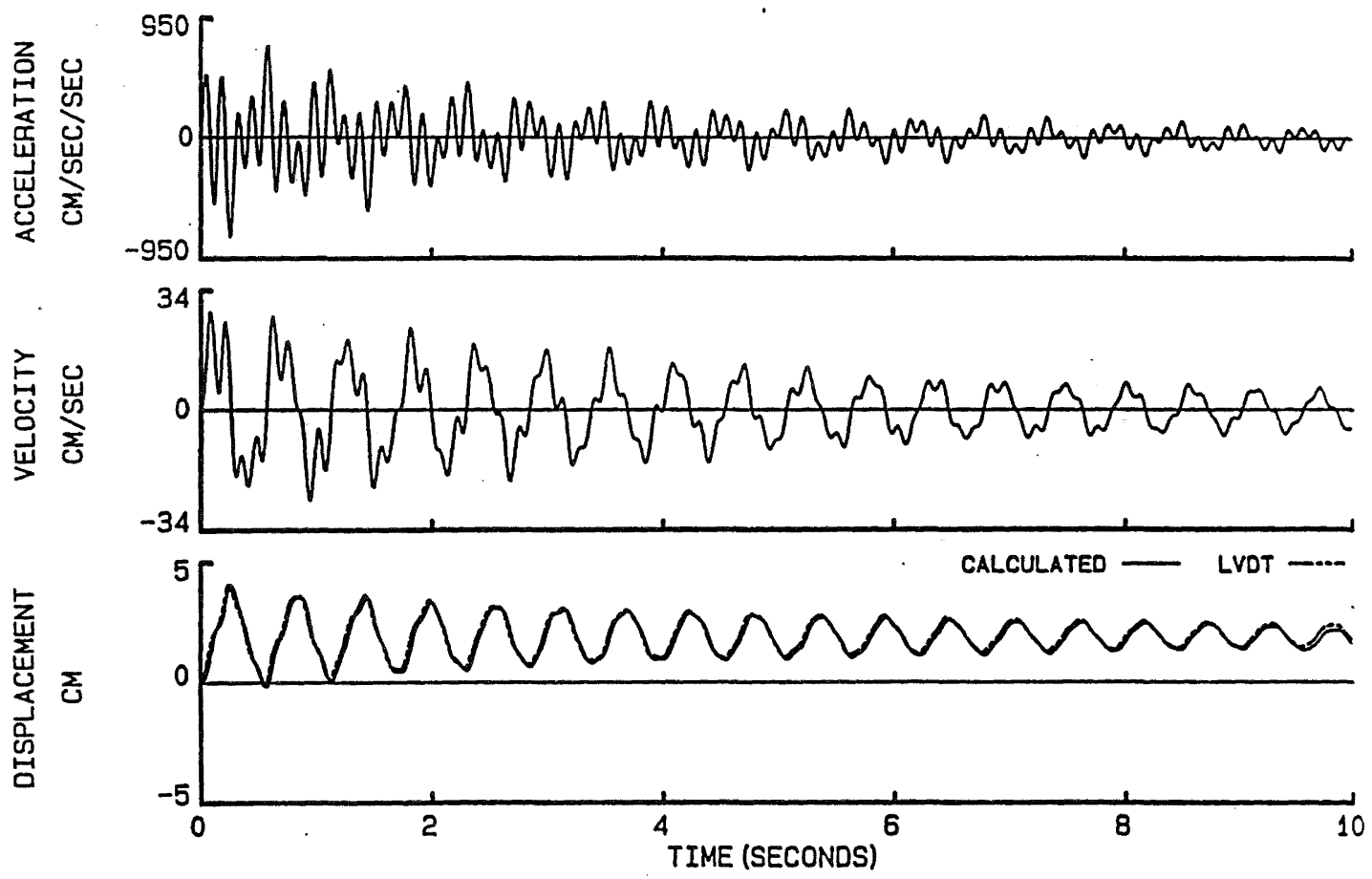

FIGURE 8. 10-SECOND RECORD

THREE STOREY FRAME MODEL 4-21-88 U.N.R.

STOREY-2 ATTENUATOR-66db LOW PASS $-12.5 \mathrm{hz}$ ORD 7 SPS-100 FILE-17 MAX ACC $=-754.16 \mathrm{CM} / \mathrm{S} / \mathrm{S}$ MAX VEL $=27.559 \mathrm{CM} / \mathrm{S}$ OFFSET DISP $=-.1977 E+01 \mathrm{CM}$

总出

925

荡

点

$$
34[
$$

0

岕 㟧

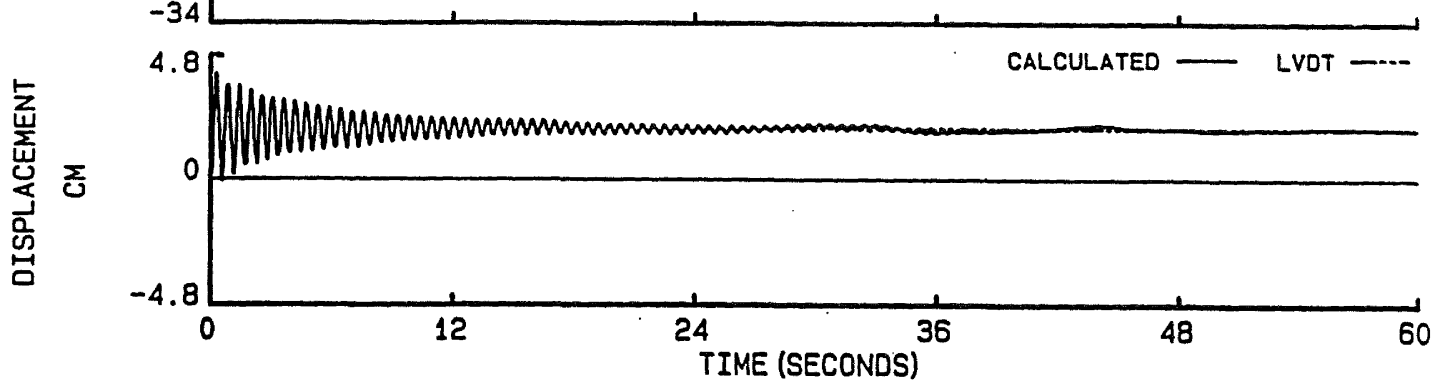

FIGURE 9. 60-SECOND RECORD 
THREE STOREY FRAME MODEL 4-21-88 U.N.R.

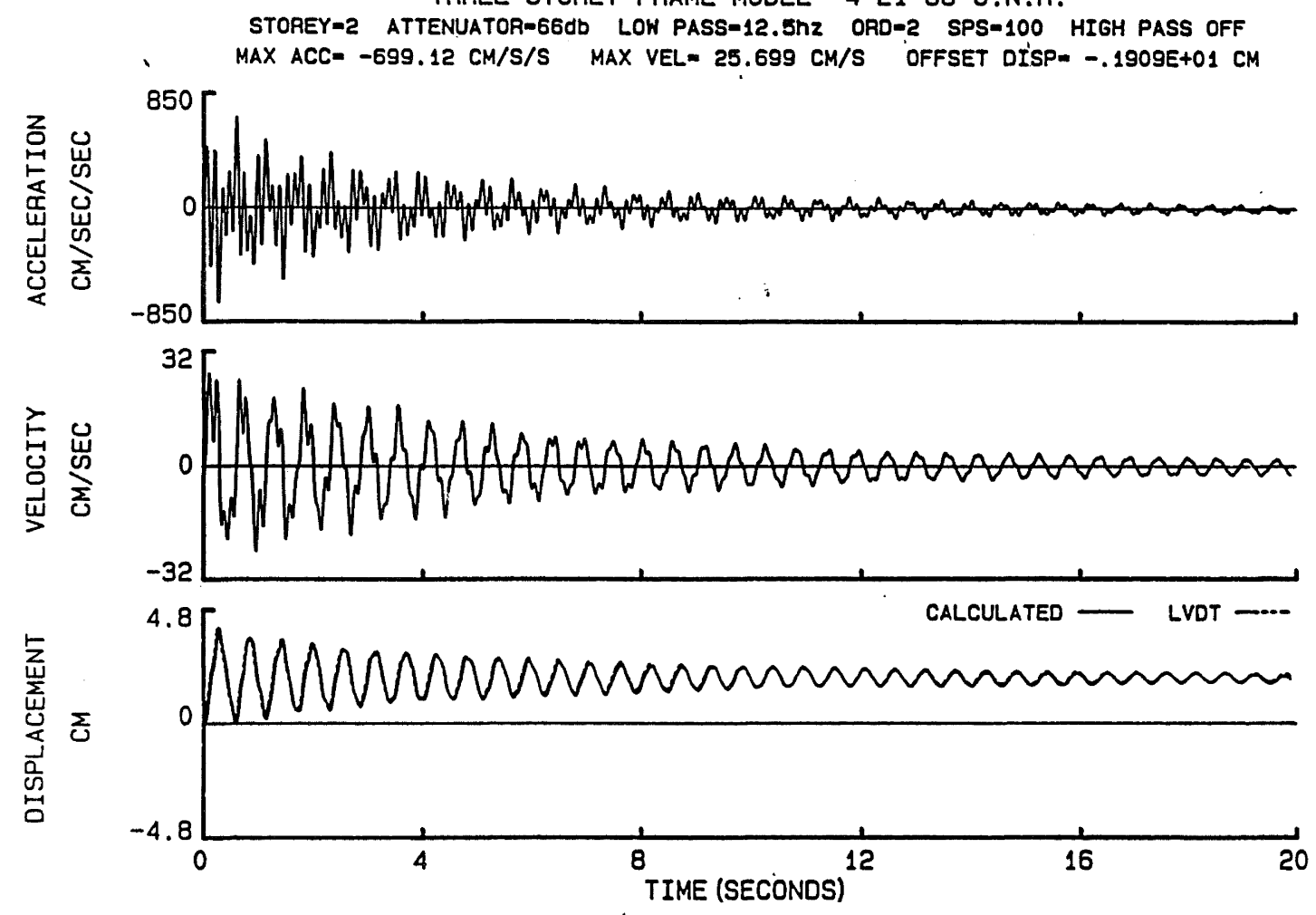

FIGURE 10. EXPERIMENT WHEN HIGH PASS FILTER IS OFF
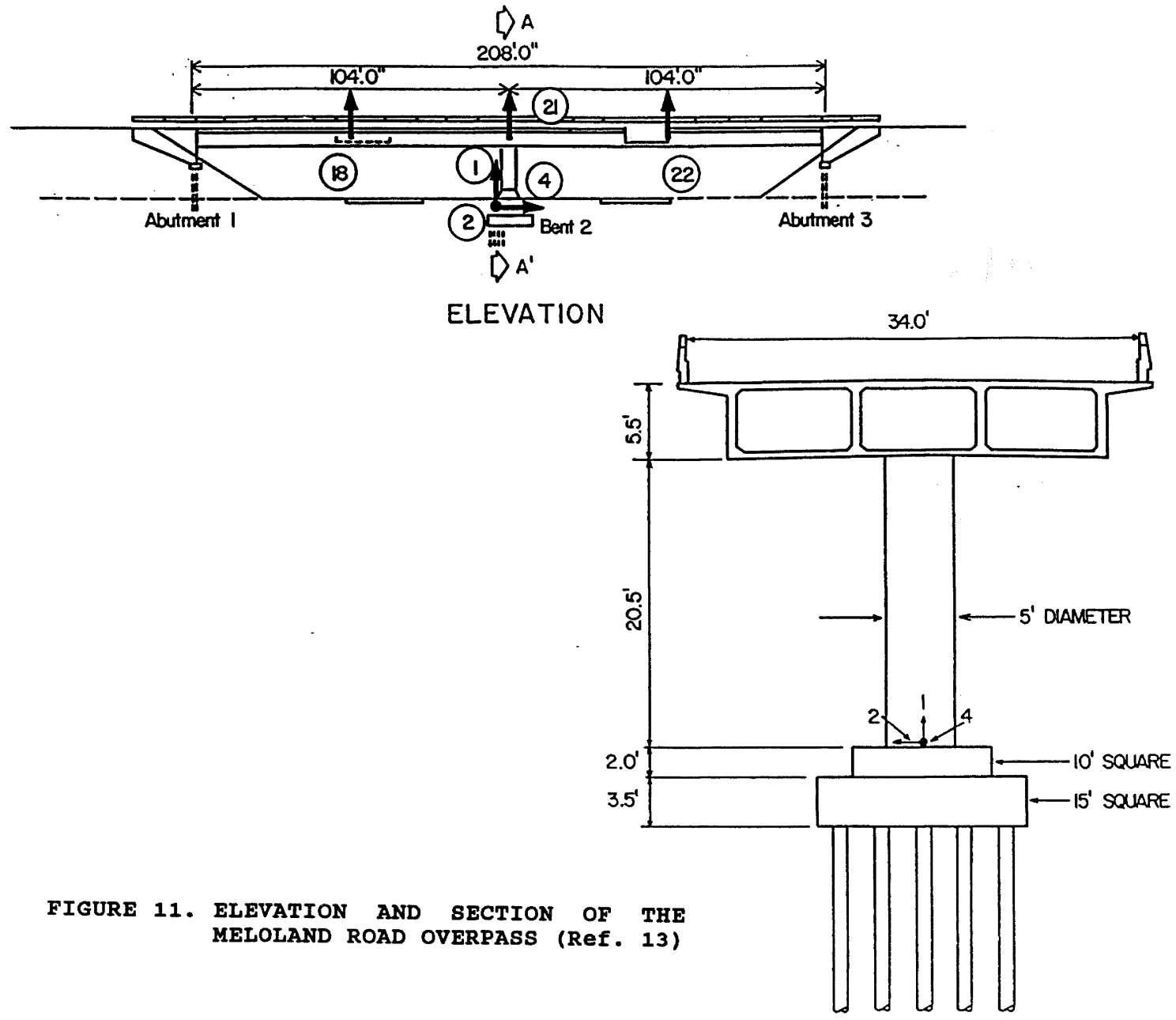
the abutments. The single central pier and the abutments are supported on pile foundations. An elevation and a section of the bridge are shown in Fig. 11 [12]. This bridge is located in a very active seismic zone near $\mathrm{El}$ Centro in Southern California, and its type is representative of many bridge structures in the area. Two levels of ram load were used for the excitation of the bridge: 21.2 kips and 141 kips. The bridge was completely instrumented with accelerometers in a sequential way so as to measure the transverse and rotational response of the bridge deck, foundations, and abutments. The accelerometers on the deck were placed at stations which were 20.67 feet apart. The acceleration time histories which were obtained during the full-scale tests were integrated to displacements using the method described in this paper. Examples of the measured acceleration records and their corresponding calculated velocity and displacement traces at the deck and the foundation level are shown in Figs. 12 and 13 respectively. The load for both of these figures was 141 kips.

Based on the calculated offset displacements, the static deformations of the bridge caused by the ram loadings were estimated. A complete description and analysis of the static deformations of the structure are provided in Ref. 9. Some selective static deformations (in centimeters) of the bridge are shown in Figs. 14-16. In Fig. 14, the calculated transverse displacement caused by the $21.2-\mathrm{kip}$ ram load is shown. Figure 15 shows the vertical release displacement (in centimeters) at the east and west sides of the bridge deck caused by the 21.2-kip ram load. Finally, Fig. 16 shows the displaced cross section of the bridge at the central pier caused by the 21.2-kip low amplitude ram load.

\section{SUMMARY}

A new baseline correction method has been developed which allows accelerograms collected during quick-release tests of full-scale structures to be doubly integrated to displacements. The method is a generalization and extension of the prior work of Brady (1966), and it allows the recovery of the offset displacement caused by the quick-release loads. Because of this development, in future dynamic response studies where detailed mode shapes are developed, it will now easily be possible to augment such studies with the complete static deformation of the structure caused by the quick-release loads. Additionally, the complete velocity response of the system will also be available as a necessary by-product of the study. The validity of the method was tested and verified by performing quick-release type experiments on a simple three-story laboratory structure. An example of the application of this technique is provided in which the method was used to calculate the static deformations of the Meloland Bridge based on the accelerogram obtained during a full-scale quick-release test of the structure.

\section{REFERENCES}

1. Al-Khafaji, A.W. and Tooley, J.R., (1986) Numerical Methods in Engineering Practice, Holt, Rinehart and winston, Inc.

2. Anderson, J.G., (1985) "Two observations About Low-Frequency Signals on Accelerograms from the October 15, 1979 Imperial Valley, California Earthquake" Earthquake Engineering and Structural Dynamics, Vol. 13, 97-108.

3. Anderson, J.G., Brune, J.N., Prince, J., Singh, S.K., Quass, $R_{\text {. , and onate, }}$ M., (1986) "Strong Ground Motion from the Michoacan Mexico, Earthquake," Science, Vol. 233

4. Brady, A.G., (1966) "Studies of Response to Earthquake Ground Motion," Earthquake Engineering Research Laboratory, California Institute of Technology, Pasadena, California.

5. Brady, A.G., Perez, V., and Mark, P.M., (1982) "Digitization and Processing of Main-Shock Ground-Motion Data from the U.S. Geological Survey Accelerograph Network," Professional Paper 1254, U.S. Geological Survey, Menlo Park, California.

6. Buckle, I.G., Douglas, B., Saiidi, M., Richardson, J., and Butterworth, J., (1987) "Field Tests of Ramp 13, Dominion Road Interchange Using Simulated Earthquake Loads," Proceedings of Pacific Conference on Earthquake Engineering, Wairakei, New Zealand, August 5-8, 1987, 19 pp.

7. Douglas, B.M., (1976) "Quick Release Puliback Testing and Analytical Seismic Analysis of a Six-span Composite Girder Bridge," Report No. FHWA-RD-76-173, Federal Highway Administration, offices of Research and Development, Washington, D.C.

8. Douglas, B.M., and Reid, W.H., (1982) "Dynamic Tests and system Identification of Bridges," ASCE Journal of the Structural Division, Vol. 108, 2295-2312.

9. Douglas, B.M. Maragakis, E.A., Nath, B., "Static Deformations of Bridges from Quick-Release Dynamic Experiments, "accepted for publication to the ASCE Journal of Structural Engineering (to appear in september 1990).

10. Hudson, E.E., (1979) Reading and Interpreting strong Motion Accelerograms, Earthquake Engineering Research Institute.

11. Iwan, W.D., Moser, M.A., and Peng, C.Y., (1985) "Some Observations on Strong-Motion Earthquake Measurement Using a Digital Accelerograph," Bulletin of the seismological society of America, Vol. 75, 1225-1246.

12. Iwan, W.D., Moser, M.A., and Peng, C.Y., (1984) "Strong Motion Earthquake Measurement Using a Digital Accelerograph, Report No. 84-02, Earthquake Engineering Research Laboratory, California Institute of Technology, Pasadena, California.

13. Rojan, C., Ragsdale, J.T., Ragget, J.D., and Gates, J.H., "Mainshock Strong-Motion Records from Meloland Road-Interstate Highway 
Overcrossing, The Imperial Valley, California Earthquake of October 15, 1979," Geological Survey Professional Paper 1254, pp. 337-383.

14. Trifunac, M.D., and Lee, V., (1973)

"Routine Computer Processing of Strong Motion Accelerograms," Report No. 73-03, Earthquake Engineering Research Laboratory, California Institute of Technology, Pasadena, California.

\section{APPENDIX I}

List of symbols

$a(t)=$ Acceleration measured by

$a_{i}=$ acceleration at time $t_{i}$

$\mathrm{a}^{*}(t)=$ corrected acceleration

$\mathrm{C}_{\mathrm{m}}=\mathrm{m}^{\text {th }}$ coefficient of the baseline correction

= constants of integration

$c_{n+2}$

$d(t)$

$\mathrm{d}_{\mathrm{i}}$ $d^{*}(t)$
= displacement record obtained by integrating the measured acceleration record

$=$ displacement at time $t_{i}$

$=$ displacement record obtained by integrating the corrected acceleration record

$\hat{d}(t) \quad=\quad$ displacement record measured by LVDT transducers

$\overline{\mathrm{a}}(\mathrm{t}$

$=$ average of the displacement record measured by LVDT transducers

$\mathrm{f}, \overline{\mathrm{f}}, \mathrm{F}=$ mathematical symbols defined in the text and used for the definition of the coefficient of multiple determination

$I_{r}$

$\mathrm{N}$

n

$\mathrm{R}^{2}$

$\mathbf{v}_{\mathbf{i}}$

$v^{*}(t)$

$\Delta \mathrm{a}_{\mathrm{i}}$

$\Delta t_{i}$ $=\quad$ integrals defined in the text and evaluated in Appendix II

$=$ number of data points

$=$ order of the polynomial of the baseline correction

$=$ coefficient of multiple determination

= velocity record obtained by integrating the measured acceleration record

$=$ velocity at time $t_{i}$

= velocity record obtained by integrating the corrected acceleration record

$=$ incremental acceleration between $t_{i}$, and $t_{i+1}$

$=$ incremental time

MELOLLAND ROAD OVERCROSSING 5-24-88 EL-CENTRO

CHANNEL-5 ATTENUATOR-BOdb LOW PASS-GOHZ FILEMHLT2F11.5 ORD-2 SPS-300 $\operatorname{MAX}$ ACC $=-211.29 \mathrm{CM} / \mathrm{S} / \mathrm{S}$ MAX VEL $=-6.6608 \mathrm{CM} / \mathrm{S}$ OFFSET DISP= .3534E+00 CM

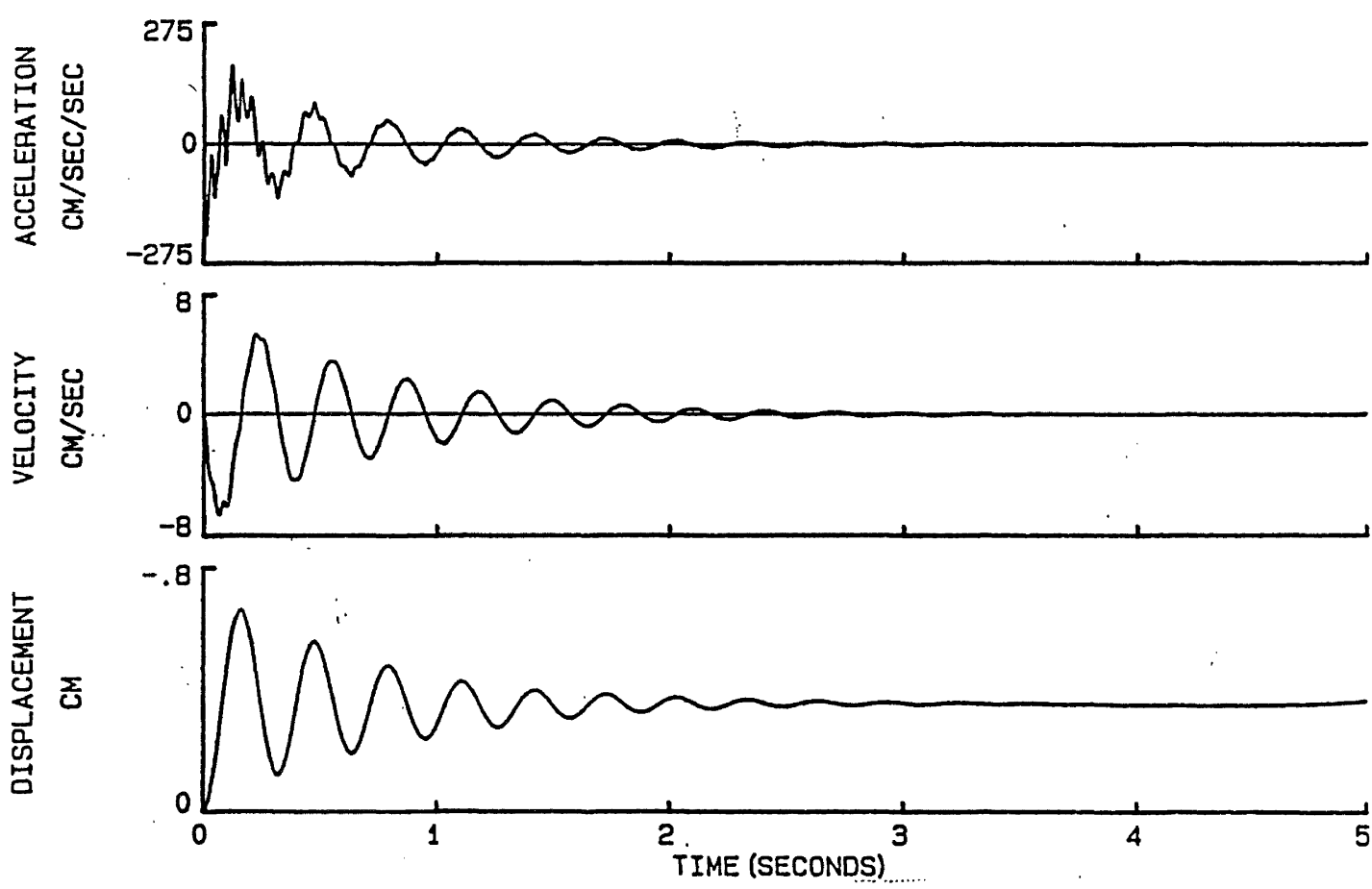

FIGURE 12. HIGH AMPLITUDE DECK LEVEL CENTRE PIER TRANSVERSE ACCERATION, VELOCITY AND DISPLACEMENT TRACES FROM THE MAY 1988 FIELD TESTS 


\section{APPENDIX II}

Evaluation of the Integrals $I_{r}$

In order to evaluate the integrals $I_{r}$ in (5) it will be assumed that the uncorrected acceleration record $a(t)$ consists of linear segments. In this case it is possible to derive a simple expression for the acceleration $a(t)$ which integrated twice will produce an expression for the displacement $d(t)$ which can be used for the evaluation of the integrals $I_{r}$. The expressions given in equation $g^{\circ}$ can be obtained for the unadjusted acceleration, velocity and displacement at any time $t$ between $t_{i}$ and $t_{i+1}$.

Substituting the expression of $d(t)$ from (9) into (5) and performing the integration yields the following expression for the integrals $I_{r}$ as given in equation 10 .

$$
\begin{aligned}
& a(t)=a_{i}+\frac{t-t_{i}}{\Delta t_{i}} \Delta a_{i}=\left(a_{i}-t_{i} \frac{\Delta a_{i}}{\Delta t_{i}}\right)+\frac{\Delta a_{i}}{\Delta t_{i}} t \\
& v(t)=v_{i}+\left(a_{i}-t_{i} \frac{\Delta a_{i}}{\Delta t_{i}}\right)\left(t-t_{i}\right)+\frac{\Delta a_{i}}{\Delta t_{i}} \frac{t^{2}-t_{i}^{2}}{2}= \\
& \left(v_{i}-a_{i} t_{i}+\frac{1}{2} t_{i}^{2} \frac{\Delta a_{i}}{\Delta t_{i}}\right)+\left(a_{i}-t_{i} \frac{\Delta a_{i}}{\Delta t_{i}}\right) t+\frac{1}{2} \frac{\Delta a_{i}}{\Delta t_{i}} t^{2} \\
& d(t)=a_{i}+\left(v_{i}-a_{i} t_{i}+\frac{1}{2} t_{i}^{2} \frac{\Delta a_{i}}{\Delta t_{i}}\right)\left(t-t_{i}\right)+\left(a_{i}-t_{i} \frac{\Delta a_{i}}{\Delta t_{i}}\right) \frac{t^{2}-t_{i}^{2}}{2}+\frac{1}{2} \frac{\Delta a_{i}}{\Delta t_{i}} \frac{t^{3}-t_{i}^{3}}{3}= \\
& \left(a_{i}-v_{i} t_{i}+\frac{1}{2} a_{i} t_{i}^{2}-\frac{1}{6} \frac{\Delta a_{i}}{\Delta t_{i}} t-i^{3}\right)+\left(v_{i}-a_{i} t_{i}+\frac{1}{2} \frac{\Delta a_{i}}{\Delta t_{i}} t_{i}^{2}\right) t+\left(a_{i}-t_{i} \frac{\Delta a_{i}}{\Delta t_{i}}\right) \frac{t^{2}}{2}+\frac{1}{6} \frac{\Delta a_{i}}{\Delta t_{i}} t^{3} \\
& I_{r}=\sum_{i=0}^{N-1}\left[\frac{1}{r+1} d_{i} \Delta t_{i}\left(t_{i+1}^{r}+t_{i+1}^{r-1} t_{i}+t_{i+1}^{r-2} t_{i}^{2}+\ldots+t_{i+1} t_{i}^{r-1}+t_{i}^{r}\right)+\right] \\
& \frac{1}{(r+1)(r+2)} v_{i}\left(\Delta t_{i}\right)^{2}\left\{r+1 t_{i+1}^{r}+r t_{i+1}^{r-1} t_{i}+\ldots+2 t_{i+1} t_{i}^{r-1}+t_{i}^{r}\right\}+ \\
& \frac{1}{6(r+1)(r+2)(r+3)(r+4)}\left\{a_{i+1}\left\{(r+1)(r+2)(r+3) t_{i+1}^{r}+r(r+1)(r+2) t_{i+1}^{r-1} t_{i}^{r}+\right\}\right\} \\
& \left\{+\ldots+2 \cdot 3 \cdot 4 t_{i+1} t_{i}^{r-1}+1 \cdot 2 \cdot 3 t_{i}^{r}\right\}+d_{i}\left\{(r+1)(r+2)(3 r+12-(r+3)) t_{i+1}^{r}+\right\} \\
& +r(r+1)(3 r+12-(r+2)) t_{i+1}^{r-1} t_{i}+\ldots+2 \cdot 3 \cdot(3 r+12-4) t_{i+1} t_{i}^{r-1}+ \\
& {\left[\left\{+1 \cdot 2 \cdot(3 r+12-3) t_{i}^{r}\right\}\right]}
\end{aligned}
$$




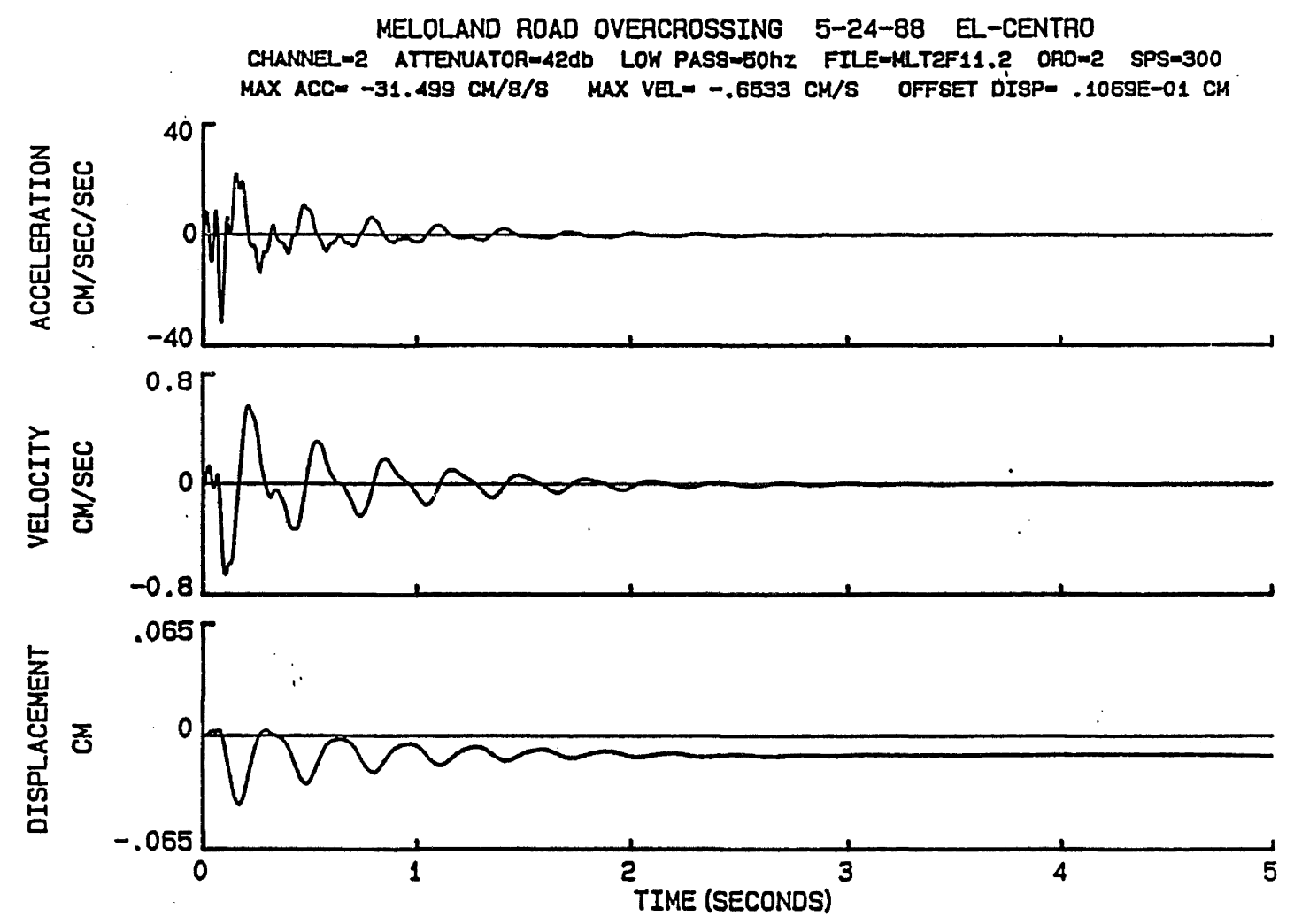

FIGURE 13. HIGH AMPLITUDE CENTRE PIER FOUNDATION TRANSVERSE ACCELERATION, VELOCITY AND DISPLACEMENT TRACES FROM THE MAY 1988 FIELD TESTS

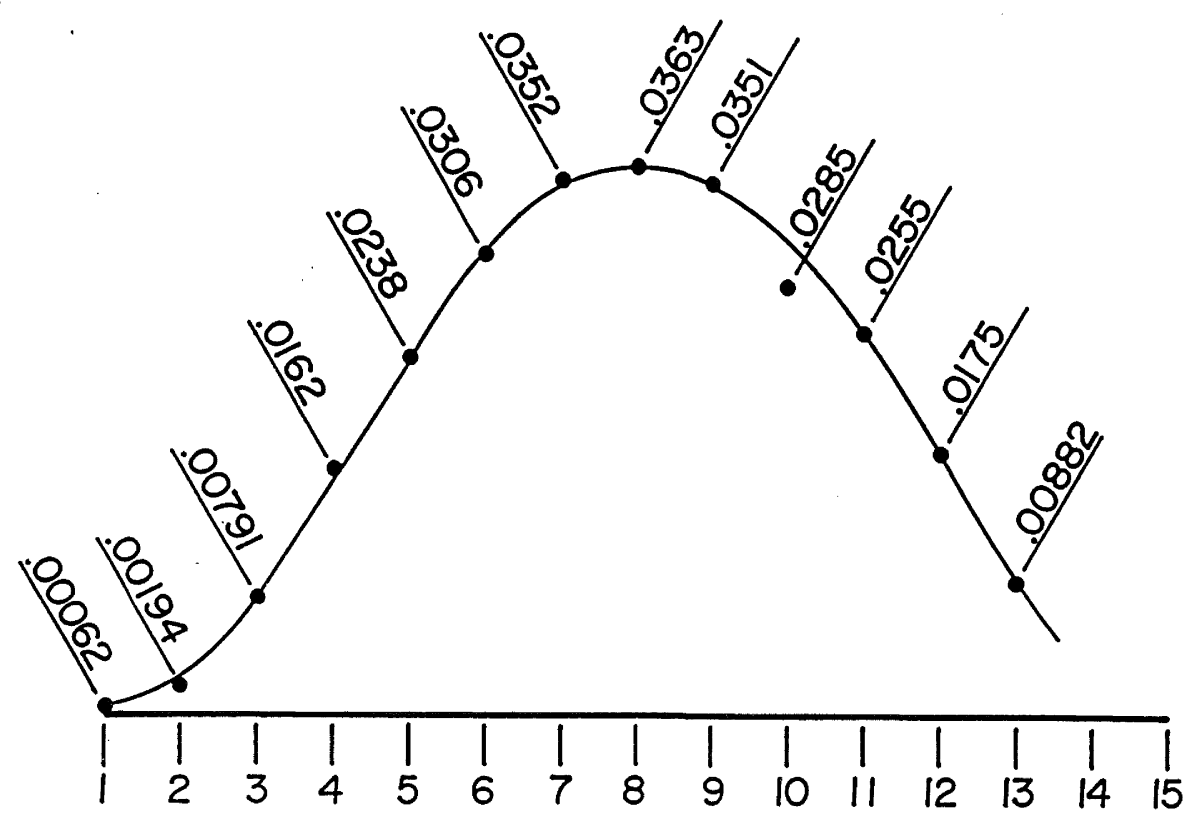

FIGURE 14. TRANSVERSE BRIDGE/ROADWAY RELAEASE DISPLACEMENT CONFIGURATION CAUSED BY THE LOW AMPLITUDE 21.2-RIP RAM LOAD 


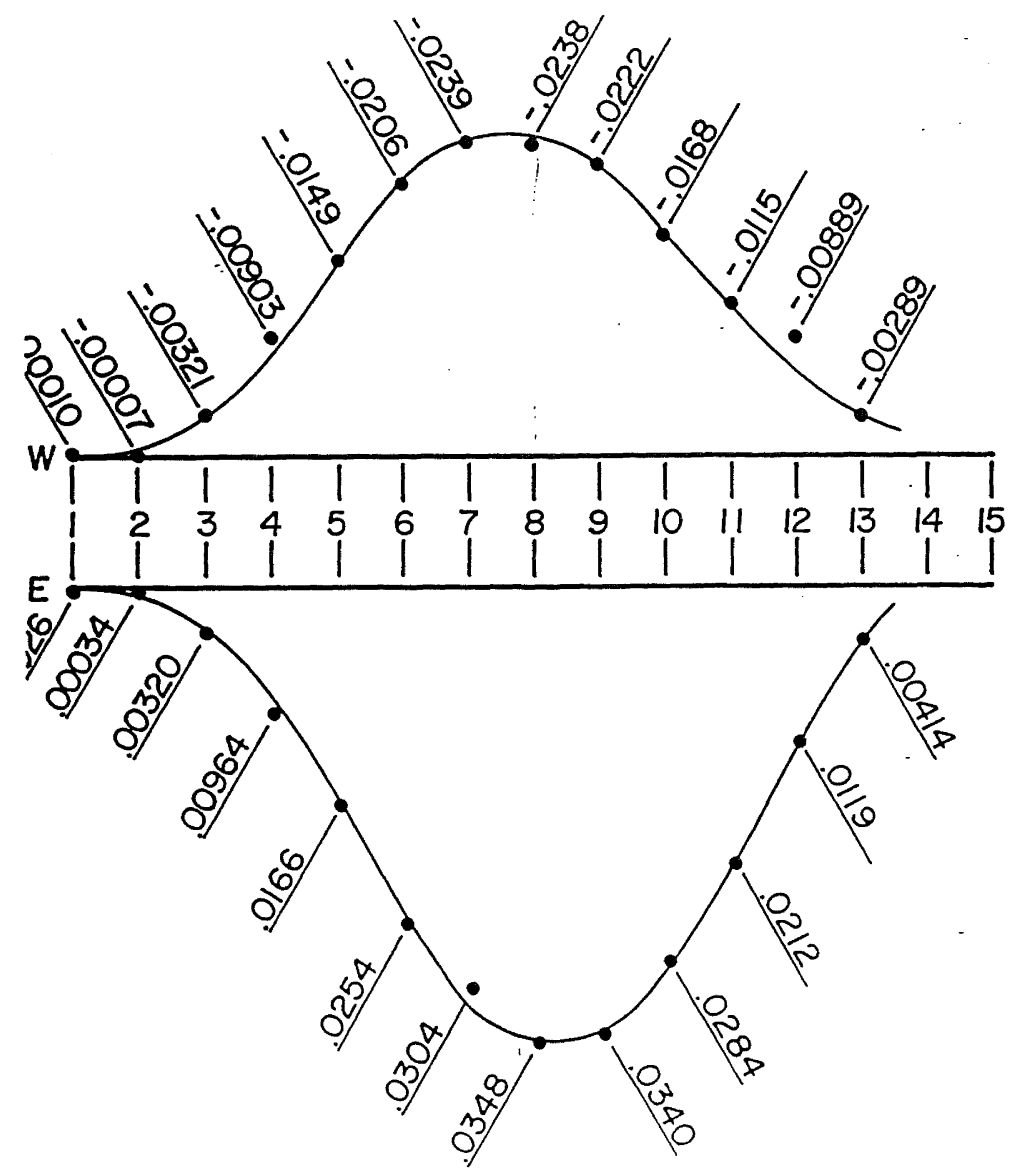

FIGURE 15. VERTICAL RELEASE DISPLACEMENT CONFIGURATION AT BOTH THE EAST AND WEST SIDES OF THE BRIDGE/ROADWAY CAUSED BY THE LOW AMPLITUDE 21.2-RIP RAM LOAD

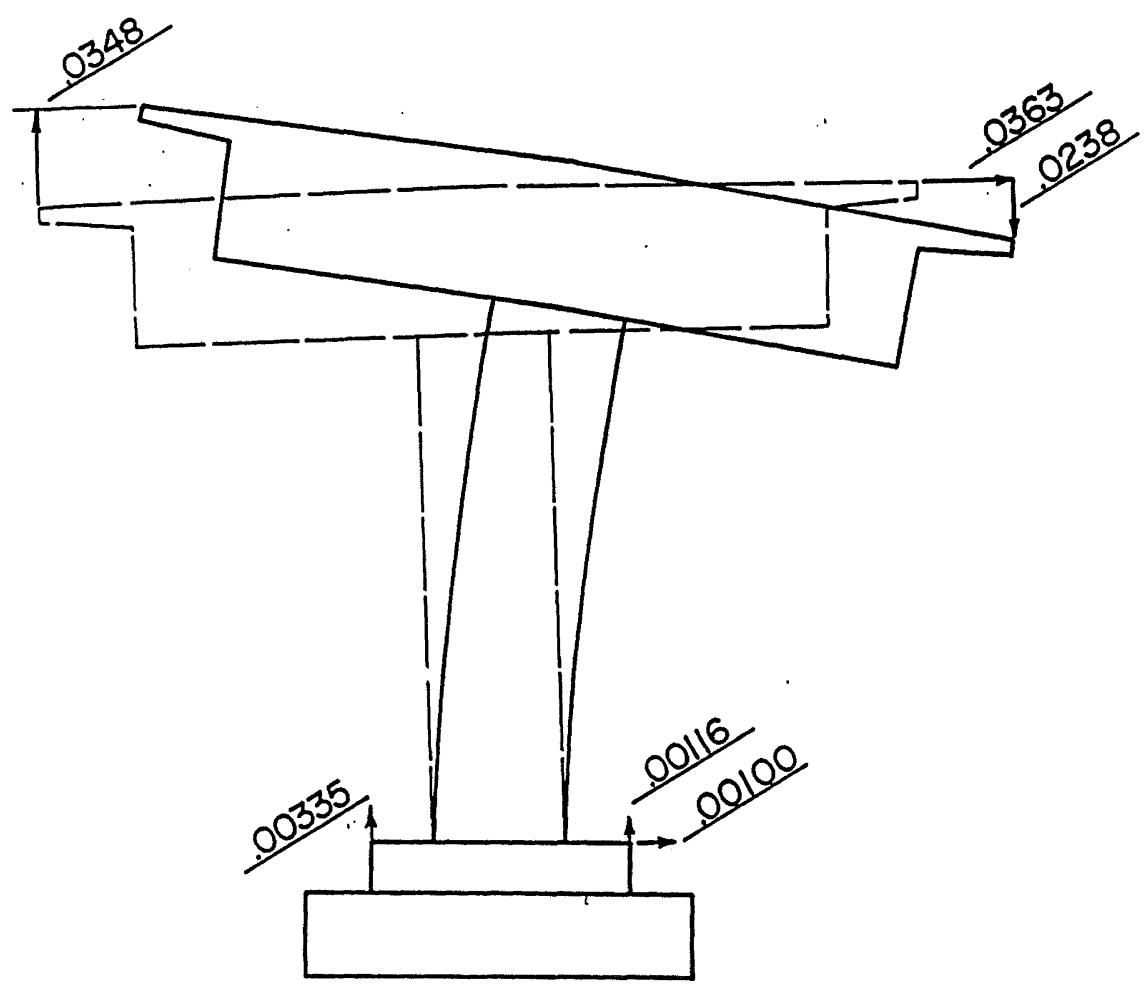

FIGURE 16. RELEASE CONFIGURATION OF THE PIER SECTION INCLUDING FOUNDATION DISPLACEMENTS CAUSED BY THE LOW AMPLITUDE 21.2-KIP RAM LOAD 